\title{
Expression of epidermal growth factors and apoptosis markers in pancreatic ductal adenocarcinoma
}

\author{
Anna Pryczynicz' ${ }^{1}$ Katarzyna Guzińska-Ustymowicz ${ }^{1}$, Jolanta Czyżewska ${ }^{2}$ \\ and Andrzej Kemona ${ }^{1}$
}

Departments of: ${ }^{1}$ General Pathomorphology and ${ }^{2}$ Clinical Laboratory Diagnostics, Medical University of Białystok, Białystok, Poland

\begin{abstract}
Background: Epidermal growth factor family members: EGF, EGFR and the c-erbB-2(HER-2/neu) are involved in the growth of pancreatic ductal carcinoma, its invasiveness and metastases. Similarly, proteins regulating apoptosis can influence the development of pancreatic cancer. The aim of our study was to assess the expressions of EGF, EGFR, c-erbB2, Bax and Bcl-xL in comparison with anatomo-clinical parameters. We also analyzed the relationship between the epidermal growth factors and apoptosis-regulating proteins. Materials and methods: The levels of these proteins were determined immunohistochemically in 29 pancreatic ductal carcinoma cases. Results: We found no correlation of EGF, EGFR, c-erbB2, Bax and Bcl-xL with age and gender of patients, or histological type and grade of malignancy (G). However, we observed a very strong correlation between EGF, EGFR, Bax, Bcl-xL and lymph node metastases $(p=0.000, p=0.001, p=0.008$, $p=0.012$, respectively) and between EGF, EGFR and distant metastases $(p=0.002, p=0.008$, respectively). Moreover, we found a correlation between Bcl-xL and c-erbB-2 $(\mathrm{p}=0.030)$ and between EGF and Bax ( $\mathrm{p}=0.041)$. Conclusions: These investigations seem to suggest that both epidermal growth factors (EGF, EGFR) and apoptosis-regulating proteins (Bax and Bcl-xL) play an essential role in lymph node involvement. Moreover EGF and EGFR are involved in distant metastases. The apoptosis markers appear to cooperate with epidermal growth factor proteins in the process of tumor spread.
\end{abstract}

Key words: pancreatic ductal adenocarcinoma, apoptosis, Bax, Bcl-xL, EGF, EGFR, c-erbB-2

\section{Introduction}

Apoptosis or programmed cell death is the major genetically regulated process of cell self-destruction. Apoptosis plays an essential role by controlling the number of cells during maturation and allows elimination of damaged or neoplastically transformed cells. Apoptosis occurs via a mitochondria-dependent or -independent pathway. The former involves enzymes called caspases, which if activated lead to cytoskeleton disintegration, chromatin fragmentation and formation of apoptotic bodies. On the other hand, caspase activation depends on the action of other proteins of the Bcl-2 family, including both caspase-activating enzymes (Bax, Bak, Bok, Bcl-xs, Bad, Bid, Bik, Bim, BMF, HRK, NOXA, BBC3) and caspase-

Correspondence: K. Guzińska-Ustymowicz, Dept. of General Pathomorphology, Medical University of Białystok, Waszyngtona Str. 13, 15-269 Bialystok, Poland; tel.: (+4885) 7485942, fax.: (+4885) 7485996, e-mail: kasia.guzinska@gmail.com inhibiting proteins (Bcl-2, Bcl-xL, Bcl-lw, Bfl-1, Mcl-1). The balance between these groups of proteins determines the occurrence of apoptosis $[1,2]$. Bax is a pro-apoptotic protein belonging to the $\mathrm{Bcl}-2$ family and containing $\mathrm{BH} 1$ and $\mathrm{BH} 2$ domains as well as $\mathrm{BH} 3$ domain through which it can form heterodimers with Bcl-2 and Bcl-xL proteins. In normal cells, Bax protein is located in the cytoplasm, whereas after apoptosis initiation, Bax passes to membranes of cell organelles, particularly to the mitochondrial membrane. It has been proved that Bax overexpression induces apoptosis in lung cancer [3]. It has been also observed that reduced Bax expression is associated with shorter survival in colorectal cancer patients [4]. Antagonistic to Bax is the anti-apoptotic protein Bcl$\mathrm{xL}$, located on the surface of the mitochondrial membrane and in the endoplasmic reticulum membrane. Bcl-xL, built up of four domains (BH1-BH4), plays an important role in the inhibition of cytochrome $\mathrm{C}$ release through binding to Bax and Bak proteins. It is also involved in the neoplastic process. According to numerous studies, $\mathrm{Bcl}-\mathrm{xL}$ overexpression contributes 
Table 1. Immunohistochemical expressions of EGF, EGFR, c-erbB-2, Bcl-xL, Bax in colorectal carcinomas in association with chosen anatomo-clinical parameters. $\mathrm{P}<0.05$ was considered statistically significant (marked bold).

\begin{tabular}{|c|c|c|c|c|c|c|}
\hline & No. & EGF & EGFR & c-erbB-2 & Bcl-xL & Bax \\
\hline $\begin{array}{l}\text { Age } \\
\quad<60 \\
\quad \geq 60\end{array}$ & $\begin{array}{l}14 \\
15\end{array}$ & $\mathrm{p}=0.844$ & $\mathrm{p}=0.209$ & $\mathrm{p}=0.511$ & $\mathrm{p}=0.553$ & $\mathrm{p}=0.525$ \\
\hline $\begin{array}{l}\text { Gender } \\
\text { male } \\
\text { female }\end{array}$ & $\begin{array}{r}23 \\
6\end{array}$ & $\mathrm{p}=\mathbf{0 . 0 3 4}$ & $\mathrm{p}=0.511$ & $\mathrm{p}=0.333$ & $\mathrm{p}=0.272$ & $\mathrm{p}=0.249$ \\
\hline $\begin{array}{l}\text { Grade of histological malignancy } \\
\text { 1. G2 } \\
\text { 2. G3 }\end{array}$ & $\begin{array}{r}25 \\
4 \\
\end{array}$ & $\mathrm{p}=0.830$ & $\mathrm{p}=0.608$ & $\mathrm{p}=0.608$ & $\mathrm{p}=0.276$ & $\mathrm{p}=0.254$ \\
\hline $\begin{array}{l}\text { Histological type of cancer } \\
\text { adenocarcinoma } \\
\text { adc. gelatinosum }\end{array}$ & $\begin{array}{r}26 \\
3\end{array}$ & $\mathrm{p}=0.686$ & $\mathrm{p}=0.868$ & $\mathrm{p}=0.868$ & $\mathrm{p}=0.207$ & $\mathrm{p}=0.186$ \\
\hline $\begin{array}{l}\text { Lymph node metastasis } \\
\text { absent } \\
\text { present }\end{array}$ & $\begin{array}{l}19 \\
10\end{array}$ & $p=0.001$ & $p=0.001$ & $\mathrm{p}=0.873$ & $\mathrm{p}=0.012$ & $p=0.008$ \\
\hline $\begin{array}{l}\text { Distant metastasis } \\
\text { absent } \\
\text { present }\end{array}$ & $\begin{array}{r}21 \\
8\end{array}$ & $\mathrm{p}=0.002$ & $\mathrm{p}=0.008$ & $\mathrm{p}=0.427$ & $\mathrm{p}=0.088$ & $\mathrm{p}=0.073$ \\
\hline
\end{tabular}

to carcinogenesis by protecting tumor cells from death $[4,5]$.

Apart from being involved in proliferation, the epidermal growth factor (EGF) may also regulate apoptosis through its inhibition [1]. EGF is a single polypeptide, built up of 53 amino acids, that plays an essential role in intercellular interactions. Cooperation between EGF of one cell and the receptor (EGFR) on the adjacent cell results in some biological effects, e.g. migration, growth or morphological changes in the cell. EGF stimulates growth or exerts a trophic effect in many tissues, including the pancreas and fibroblasts, and plays a major role in proliferation, differentiation and maturation of the embryonic intestine [6,7]. However, EGF and EGFR, apart from being involved in normal development, take part in neoplastic transformation. Increased EGF and EGFR expressions have been observed in various malignancies, including carcinoma of the pancreas [8], stomach [9], liver [10], and also brain tumors [11]. Literature widely describes neoplastic HER-2/neu (cerbB-2) oncogene, which codes the trans-membrane glycoprotein, closely related to EGFR. Overexpression of c-erbB-2 has been found in carcinoma of the breast [12], lungs [13] and stomach [14].

The study objective was the immunohistochemical assessment of the expressions of the apoptosisregulating proteins $\mathrm{Bcl}-\mathrm{xL}$ and $\mathrm{Bax}$ as well as epidermal growth factor proteins EGF, EGFR c-erbB-2 in pancreatic ductal carcinoma in correlation with chosen anatomo-clinical parameters.

\section{Materials and methods}

Tissue samples. The study group consisted of 29 patients, with pancreatic ductal adenocarcinoma, who were operated on in the Surgical Ward of the J. Śniadecki Hospital in Białystok. Sections, $5 \mu \mathrm{m}$ thick, were cut from paraffin blocks and stained with hematoxylin and eosin $(\mathrm{H}+\mathrm{E})$. The routine histopathological assessment of the sections referred to the histological type, malignancy grade $(\mathrm{G})$, clinico-pathological pTN status, regional lymph node involvement and presence of distant metastases.

Immunohistochemistry. The protein expression was evaluated by immunohistochemical reaction using antibodies for Bax (Bax, P-19, sc-526-G, Santa Cruz Biotechnology), Bcl-xL (Bcl$\mathrm{xL}, \mathrm{N}-19$, sc-492-G, Santa Cruz Biotechnology), EGF (EGFSigma, clone EGF-10; Sigma-Aldrich, Poland), EGFR (Clone: H11, DAKO, Poland), c-erbB-2 (NCL-c-erbB-2-316, Novocastra, Poland). A standard labeled streptavidin biotin (LSAB) method protocol, described by DAKO (LSAB+HRP Kit, DAKO) was used. The reaction products were visualized with diaminobenzidine DAB (DAKO/S3000/Poland). A semiquantitative method was used to evaluate EGF, EGFR, c-erbB-2 expression, which was defined as positive (reaction present in $>30 \%$ of tumor cells) or negative (lack of reaction or reaction present in $<30 \%$ of cells). The reaction to Bax and Bcl-xL was evaluated according to the following criteria: 1-negative or weak (lack of reaction or reaction present in $<5 \%$ cells), 2 -moderate (reaction present in $6-30 \%$ of cells) and 3 -strong (reaction present in $>30 \%$ of cells).

Statistical analysis. The percentage of the reaction-positive cells was calculated in 500 neoplastic cells in each study sample at $400 \times$ magnification. Spearman's correlation coefficient and $\chi^{2}$ test were used for statistical analysis. A p-value of $<0.05$ was considered statistically significant. 

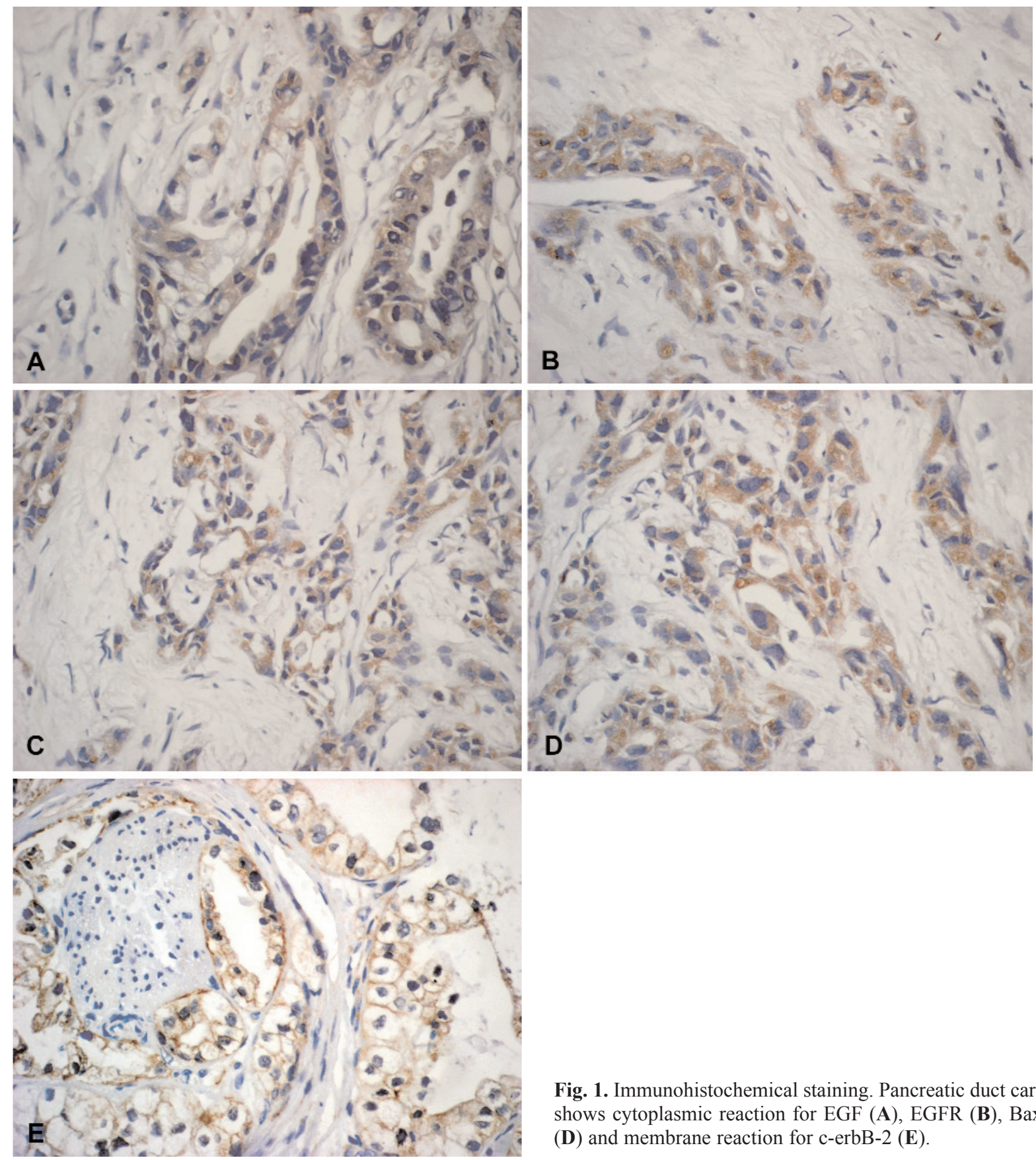

Fig. 1. Immunohistochemical staining. Pancreatic duct carcinoma tissue shows cytoplasmic reaction for EGF (A), EGFR (B), Bax (C), Bcl-xL (D) and membrane reaction for c-erbB-2 (E).

\section{Results}

The study group included 6 women and 23 men aged 41-74 years. No expression of epidermal growth factor was found in normal pancreas, whereas the expressions of EGF, EGFR and c-erbB-2 in pancreatic ductal carcinoma were elevated. In normal pancreas, the expressions of the apoptosis-regulating proteins (Bax and $\mathrm{Bcl}-\mathrm{xL}$ ) were found to be low in the cytoplasm, whereas in ductal pancreatic cancer they were either low, moderate or high. Statistical analysis revealed no correlation of patients' age, tumor histological type and malignancy grade with the expressions of EGF, EGFR,

c-erbB-2, Bax and Bcl-xL. Statistically significant relationship was found between EGF expression and patients' gender $(\mathrm{p}=0.034)$. A relationship was also observed between lymph node involvement and the expressions of EGF, EGFR, Bax and Bcl-xL ( $\mathrm{p}=0.001$, $p=0.001, p=0.008, p=0.012$, respectively). The expressions of EGF and EGFR were also found to correlate with the presence of distant metastases $(p=0.002$, $\mathrm{p}=0.008$, respectively) (Table 1 ). Moreover, a statistically significant correlation was revealed between the expression of EGF and Bax $(p=0.041)$ and between $c-$ erbB-2 and Bcl-xL ( $\mathrm{p}=0.030)$ (Table 2). 
Table 2. Associations between proteins: EGF, EGFR, c-erB-2, $\mathrm{Bcl}-\mathrm{xL}$ and $\mathrm{Bax} . \mathrm{P}<0.05$ was considered significant (marked bold).

\begin{tabular}{|l|c|c|c|c|c|}
\hline & EGF & EGFR & c-erbB-2 & Bcl-xL & Bax \\
\hline EGF & - & NS & NS & NS & $\mathbf{p = 0 . 0 4 1}$ \\
\hline EGFR & NS & - & NS & NS & NS \\
\hline c-erbB-2 & NS & NS & - & $\mathbf{p = 0 . 0 3 0}$ & NS \\
\hline Bcl-xL & NS & NS & $\mathbf{p = 0 . 0 3 0}$ & - & NS \\
\hline Bax & $\mathbf{p = 0 . 0 4 1}$ & NS & NS & NS & - \\
\hline
\end{tabular}

\section{Discussion}

Processes of cell growth, proliferation and differentiation as well as programmed death are regulated by various factors. Disturbances in these processes lead to the growth of neoplastic cells, their uncontrolled proliferation, aggressiveness and metastasizing to other tissues. We found a correlation of EGF and EGFR expressions with anatomo-clinical parameters, such as lymph node involvement. Moreover, increased expressions of EGF and EGFR were found to correlate with the presence of distant metastases. Thus, these proteins play a role in spread of ductal pancreatic cancer. Similar results have been reported by Yamanaka [15], who found EGF, EGFR and c-erbB-2 to correlate considerably with metastases to adjacent tissues. Also Zhang et al. have demonstrated that EGFR expression can help in the assessment of malignancy, progression and metastasizing of ductal pancreatic cancer [16]. In our study, enhanced expressions of Bax and Bcl-xL correlate considerably with the presence of lymph node involvement. However, little is still known about the effect of apoptosis-regulating proteins (Bax and Bcl$\mathrm{xL}$ ) on metastasis formation. Ghaneh et al. [17] have presented an overall comparison of the role of these proteins in survival rate of patients with ductal pancreatic cancer. The expression of the apoptosis-stimulating Bax is associated with a considerably longer survival in patients with ductal pancreatic cancer, whereas the expression of the apoptosis-inhibiting $\mathrm{Bcl}-\mathrm{xL}$ is related to their shorter survival. Thus, the coefficient between the anti-apoptotic Bcl-xL and pro-apoptotic Bax may play a key role in determination of survival of neoplastic cells. More accurate studies in this field might determine whether this coefficient can be a good diagnostic marker in ductal pancreatic cancer.

Moreover, in our study, EGF correlated with Bax expression, whereas c-erbB-2 with Bcl-xL expression. The results indicate that the epidermal growth factor proteins are related to the apoptosis-regulating proteins. The epidermal growth factor family receptors are trans-membrane proteins, with the intracellular tyrosine kinase domain. Ligand-induced receptor stim- ulation (EGF) causes activation of tyrosine kinase, thus initiating a cascade of intracellular signaling processes terminated by various biochemical changes such as transcription, differentiation or stimulation of cellular proliferation. Moreover, the activated tyrosine kinase induces a number of transformations via phospatidylinositol 3 kinase (AKT pathway). Phosphorylation and activation of the AKT cascade leads to the inhibition of pro-apoptotic proteins (e.g. Bax, Bak, $\mathrm{Bad})$ and hence to apoptosis suppression $[1,18]$. Thus, as revealed in our study, increased expression of EGF protein in ductal pancreatic cancer inhibits the action of pro-apoptotic Bax protein. Neoplastic cells proliferate freely and do not undergo apoptosis, which leads to cancer growth and adaptation to new locations. Also the expression of c-erbB-2 receptor has been found to correlate statistically significantly with the expression of Bcl-xL; however, these correlations have not been yet reported and require further investigations. Thus, there is a relationship of growth factors with the apoptosis-regulating proteins and with their involvement in cancer progression via metastasizing. There is a search for EGFR inhibitor that would inhibit AKT pathway activation; apoptosis would not be suppressed, making neoplastically transformed cells die [18]. This would allow implementation of therapy that would inhibit further progression of ductal pancreatic cancer and prolong patients' survival.

\section{References}

[ 1] Hougardy BM, Maduro JH, J Van Der Zee AG, et al. Clinical potential of inhibitors of survival pathways and activators of apoptotic pathways in treatment of cervical cancer: changing the apoptotic balance. Lancet Oncol. 2005;6:589-598.

[2] Chao DT, Korsmeyer SJ. BCL-2 family: regulators of cell death. Annu Rev Immunol. 1998;16:395-419.

[ 3] Coll JL, Negoescu A, Louis N, et al. Antitumor activity of bax and p53 naked gene transfer in lung cancer: in vitro and in vivo analysis. Hum Gene Ther. 1998;20:2063-2074.

[4] Ogura E, Senzaki H, Yamamoto D, et al. Prognostic significance of Bcl-2, Bcl-xL/S, Bax and Bak expression in Colorectal carcinoma. Oncol Rep. 1999;6:365-369.

[ 5] Miyamoto Y, Hosotani R, Wada M, et al. Immunohistochemical analysis of Bcl-2, Bax, Bcl-X, and Mcl-1 expression in pancreatic cancer. Oncology. 1999;56:73-82.

[6] Dembinski A, Grogory H, Konturek SJ, et al. Thropic action of epidermal growth factor on the pancreas an gastroduodenal mucosa in rats. $J$ Physiol. 1982;325:35-42.

[ 7] Weaver LT, Walker WA. Epidermal growth factor and the developing human gut. Gastroenterology. 1988;94:845-847.

[ 8] Durkin AJ, Bloomston PM, Rosemburgy AS, et al. Defining the role of the epidermal growth factor receptor in pancreatic cancer grown in vitro. Am J Surg. 2003;186:431-436.

[ 9] Takemura S, Yashiro M, Sunami T, et al. Novel models for human scirrhous gastric carcinoma in vivo. Cancer Sci. 2004; 95:893-900.

[10] Borlak J, Meier T, Halter R, et al. Epidermal growth factorinduced hepatocellular carcinoma: gene expression profiles in precursor lesions, early stage and solitary tumors. Oncogene. 2005;24:1809-1819. 
[11] Held-Feindt J, Lutjohann B, Ungefroren H, et al. Interaction of transforming growth factor-beta (TGF-beta) an epidermal growth factor (EGF) in human glioma cells. $J$ Neurooncol. 2003;63:117-127.

[12] Slamon DJ, Clark GM, Wong SG, et al. Human breast cancer: Correlation of relapse and survival with amplification of the cerbB-2/neu oncogene. Science. 1987;235:177-182.

[13] Weiner DB, Nordberg J, Nowell PC, et al. Expression of the neu gene encoded protein (p185 erB-2) in human non-small cell carcinomas of the lung. Cancer Res. 1990;50:421-425.

[14] Yokota J, Yamamoto T, Miyajima N, et al. Genetic alternations of the c-erbB-2 oncogene occur frequently in tubular adenocarcinoma of the stomach and are often accompanied by amplification of the v-erbA homologue. Oncogene. 1988; 2:283-287.

[15] Yamanaka Y. The immunohistochemical expressions of epidermal growth factors, epidermal growth factor receptors and
c-erbB-2 oncoprotein in human pancreatic cancer. Nippon Ika Daigaku Zasshi. 1992;59:51-61.

[16] Zhang L, Yuan SZ. Expression of c-erbB-2 oncogene protein, epidermal growth factor receptor, and TGF-betal in human pancreatic ductal adenocarcinoma. Hepatobiliary Pancreat Dis Int. 2002;1:620-623.

[17] Ghaneh P, Kawesha A, Evans JD, et al. Molecular markers in pancreatic cancer. J Hepatobiliary Pancreat Surg. 2002;9:111.

[18] Bruns CJ, Solorzano CC, Habrison MT, et al. Blockade of epidermal growth factor receptor signaling by a novel tyrosine kinase inhibitor leads to apoptosis of endothelial cells and therapy of human pancreatic carcinoma. Cancer Res. 2001;7:2563-2572.

Submitted: 5 March, 2009 Accepted after reviews: 16 August, 2009 